\title{
Superhard Coatings of the (Zr-Ti-Si)N and (Ti-Hf-Si)N Systems Produced by Vacuum-Arc Deposition from a Separated Flow
}

\author{
V. M. Beresnev ${ }^{a}{ }^{*}$, S. A. Klimenko ${ }^{b}{ }^{* *}$, I. N. Toryanik ${ }^{a}$, A. D. Pogrebnjak ${ }^{c}$, O. V. Sobol ${ }^{\prime d}$, \\ P. V. Turbin ${ }^{a, e}$, S. S. Grankin ${ }^{a}$ \\ ${ }^{a}$ Karazin Khar'kiv National University, \\ pl. Svobody 4, Khar'kov, 61022 Ukraine \\ ${ }^{b}$ Bakul Institute for Superhard Materials, \\ National Academy of Sciences of Ukraine, \\ vul. Avtozavods'ka 2, Kiev, 04074 Ukraine \\ ${ }^{c}$ Sumy State University, ul. Rimskogo-Korsakova 2, Sumy, 40007 Ukraine \\ ${ }^{d}$ Khar'kivskii Polytechnic Institute National Technical University, \\ ul. Frunze 21, Khar'kiv, 61002 Ukraine \\ ${ }^{e}$ Scientific Physico-Technological Center of the Ministry of Education \\ and National Academy of Sciences of Ukraine, sq. Svobody 6, Khar'kiv, 61022 Ukraine \\ *e-mail: beresnev-sept@yandex.ru \\ **e-mail:klm@ism.kiev.ua \\ Received July 16, 2013
}

\begin{abstract}
Multicomponent hard coatings based on nitrides of Si-doped transition metals have been produced by vacuum-arc deposition with the use of a RF generator and separation of an ion-plasma flux. Physico-mechanical and tribotechnical characteristics of coatings have been studied. The possibility of their use as efficient protective coatings has been shown.
\end{abstract}

DOI: $10.3103 /$ S1063457614010055

Keywords: protective coatings, vacuum-arc deposition, nitrides of metals, cutting tools.

\section{INTRODUCTION}

One of the priority directions of the modern science and technology is the development of new materials on the basis of multicomponent alloys, nanocomposite coatings, and analysis of their physico-mechanical and tribological characteristics [1,2].

To produce multicomponent and multilayer coatings, the ion-plasma deposition methods are most-used in the industry, in particular, magnetron sputtering [3] and vacuum-arc deposition [4]. The use of ion-plasma methods makes it possible to produce multicomponent coatings of different materials by mixing plasma streams from several sources or by sputtering of a cathode, which contains various components in its composition. Of greatest scientific interest are the methods, the use of which makes possible the formation of multicomponent coatings by conventional devices with one cathode containing necessary components in required ratios. The advances of technologies of applying nanocomposite coatings by ion-plasma methods require a further improvement of the known sputtering systems and development of fundamentally new devices [5, 6]. Synthesized multicomponent coatings have high operational characteristics due to the stabilities of the structure and composition, which are characterized by the minimum Gibbs energy.

Of refractory compounds that demonstrate high functional characteristics nanocrystalline composites produced as interstitial solid solutions based on nitrides of titanium, zirconium, hafnium, silicon, etc. take up a special place $[7,8]$.

The aim of the present study was to develop superhard multicomponent nitride systems based on solid solutions produced by sputtering all-metal cathodes using a vacuum-arc deposition from a separated beam and RF low-energy ion treatment and to study physico-mechanical properties of the resulting coatings. The use of separated ion-plasma flux will make it possible to practically get rid of a drop fraction in the coatings formed. 


\section{EQUIPMENT AND METHODS OF INVESTIGATIONS}

To produce a target of a multicomponent spray, we used electron-beam melting. Evaporable cathodes of the following compositions $64.2 \mathrm{Ti}+32.1 \mathrm{Hf}+3.7 \mathrm{Si}$ and $65 \mathrm{Zr}+25 \mathrm{Ti}+10 \mathrm{Si}(\mathrm{wt} \%)$ were produced.

Coatings were deposited by the vacuum-arc method on a Bulat- 6 device equipped with a RF-generator [6] and separating unit as a magnetic $L$ filter [9].Technological parameters of the deposition are given in Table 1.

Table 1. Technological parameters of the coatings deposition

\begin{tabular}{c|c|c|c|c|c}
\hline $\begin{array}{c}\text { Evaporable } \\
\text { material }\end{array}$ & $\begin{array}{c}\text { Material } \\
\text { of coating }\end{array}$ & $\begin{array}{c}\text { Arc current } \\
I_{a}, \mathrm{~A}\end{array}$ & $\begin{array}{c}\text { Nitrogen pressure, } \\
p \mathrm{~N}, \mathrm{~Pa}\end{array}$ & $\begin{array}{c}\text { Bias voltage, } \\
U_{\mathrm{RF}}, \mathrm{V}\end{array}$ & Comments \\
\hline $\mathrm{Zr}+\mathrm{Ti}+\mathrm{Si}$ & $(\mathrm{Zr}-\mathrm{Ti}-\mathrm{Si}) \mathrm{N}$ & 110 & 0.3 & 100 & Pulse RF \\
& & & 0.8 & 200 & stimulation, \\
& & & & 100 & magnetic \\
& & & 0.3 & 200 & separation \\
& & & & 100 & \\
& & & 0.8 & 200 & \\
& & & & 100 & \\
& & & & 200 & \\
\hline
\end{tabular}

The coatings were studied using a Quanta 200 3D (FEI Company, USA) scanning electron microscope and JEM 2010F (JEOL Ltd., Japan) transmission electron microscope. The phase composition was analyzed by a DRON-4 X-ray diffractometer in a $\mathrm{CuK} \alpha$ radiation. Tribotechnical tests were conducted on a High Temperature Tribometer friction machine (CSM Instruments, Swiss) by a "ball-disk" scheme in air at a temperature of 30,300 , and $500^{\circ} \mathrm{C}$. As a counterbody a ball $6 \mathrm{~mm}$ in diameter of an $\mathrm{Al}_{2} \mathrm{O}_{3}$ certified sintered ceramics was used. Disks, to which coatings were applied, were made of the steel 45 (55 HRC) of diameter $50 \mathrm{~mm}$ and $5 \mathrm{~mm}$ in thickness. The test load was $3.0 \mathrm{~N}$ and the sliding rate was $10 \mathrm{~cm} / \mathrm{s}$. We studied the friction coefficients and wear rates of coatings and a counterbody. To define the adhesion/cohesion strength, resistance to scratching, and fracture mechanism, we used a Revest scratch-tester (CSM Instruments, Swiss).

\section{RESULTS AND DISCUSSION}

The results of our studies of the effect of technological parameters of applying (TiHfSi) $\mathrm{N}$ coatings on their structural state are listed in Table 2.

During the beam separation in the deposited coatings of the above a texturing of a different degree is observed depending on the deposition parameters. If a rather low $(100 \mathrm{~V})$ potential is applied to the substrate there forms a texture with the $\{110\}$ axis. In this case the coating structure is characterized by the presence of textured and random-orientation crystallites. A volume concentration of textured crystallites is about 40 vol $\%$ of the total volume, and their lattice constant increased as compared with random-orientation crystallites. The most probable reason for the increase of the lattice constant may be an inhomogeneous distribution of the hafnium atoms in a coating (they are mainly located in the lattice sites of textured crystallites).

Table 2. Characteristics of coatings of the (Ti-Hf-Si) N system, produced by vacuum-arc deposition with a magnetic separation of the beam

\begin{tabular}{c|c|c|c|c|c}
\hline No. of a sample & $\begin{array}{c}\text { Nitrogen } \\
\text { pressure } p_{N}, \mathrm{~Pa}\end{array}$ & $\begin{array}{c}\text { Bias voltage } \\
U_{\mathrm{RF}}, \mathrm{V}\end{array}$ & $\begin{array}{c}\text { Parameter of the } \\
\text { fcc lattice, nm }\end{array}$ & $\begin{array}{c}\text { Mean size } \\
\text { of crystallites, nm }\end{array}$ & $\begin{array}{c}\text { Hf content of the } \\
\text { (Ti Hf)N } \\
\text { solid solution, at \%* }\end{array}$ \\
\hline 37 & 0.6 & -100 & 0.4337 & 5.0 & 33 \\
31 & 0.8 & -200 & 0.4290 & 6.7 & 19 \\
\end{tabular}

Note. *The calculation was made by Vegard law from the lattice constants of the solid solution (the effect of macrostresses on the shift of diffraction lines was not allowed for).

The texture formation results in an increase of the crystallites mean size in the direction of the drop of filmforming particles (perpendicularly to the plane of the growing surface). For example, the mean size of crystal- 
lites in a random-oriented fraction is $6.7 \mathrm{~nm}$, while in the textured fraction it is notably higher and makes $10.6 \mathrm{~nm}$.

As the bias voltage increases to $200 \mathrm{~V}$ the formed coatings have lower mean size of crystallites, namely, to $5.0 \mathrm{~nm}$. In this case the concentration of the textured crystallites fraction (with the $\{001\}$ texture axis in our case) decreases considerably (below $20 \mathrm{vol} \%$ ). It should be noted that an enhancement of the accelerating voltage from 100 to $200 \mathrm{~V}$ (i.e., an increase of the plasma stream energy) leads to the formation of the lattice having equal constants both in the textured and random-oriented fractions. In this case, however, the lattice constant value exceeds its value for the random-oriented fraction when a low voltage is applied to the substrate and makes $0.4237 \mathrm{~nm}$.

The analysis of the (TiHfSi) N coating using a transmission electron microscopy showed that the nanograins size corresponds to the data of XRD analysis, i.e., the formation of an ultradispersed structure with the mean size of crystallites within 3-10 nm is observed. A dark-field image of such a structure is given in Fig. 1a and a SAD pattern of a (TiHfSi) $\mathrm{N}$ coating region is given in Fig. $1 \mathrm{~b}$.

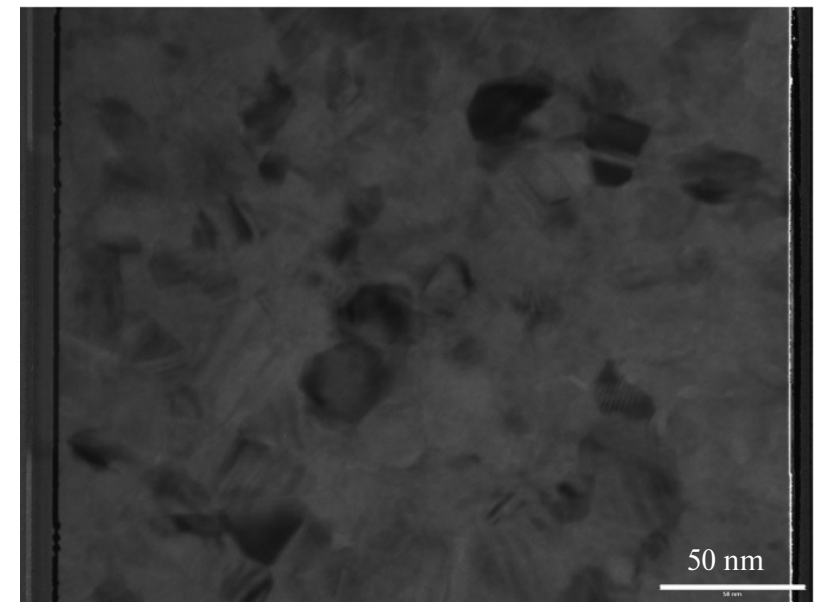

(a)

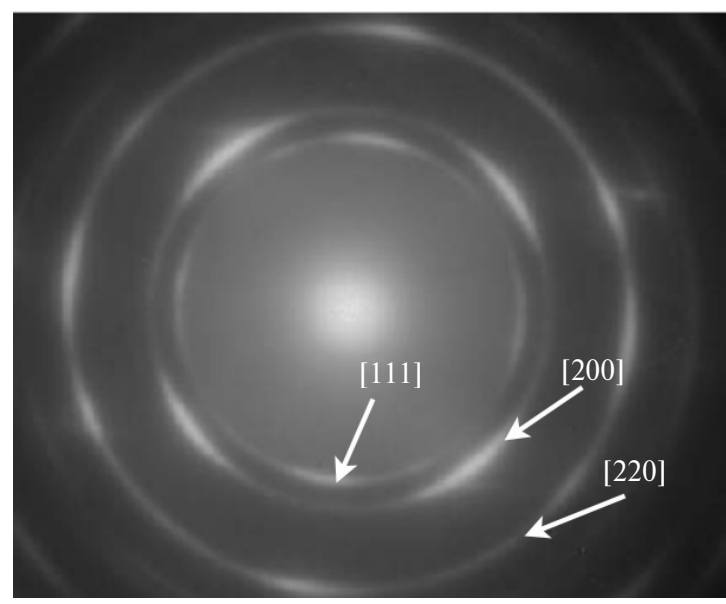

(b)

Fig. 1. Photos of the structure regions of a (TiHfSi)N composite coating taken using a JEM 2010F transmission electron microscope: a dark-field image of the nanograin structure (a), SAD pattern of a coating region (b).

Figure 2 shows a diffraction pattern of a $(\mathrm{ZrTiSi}) \mathrm{N}$ coating produced by a vacuum-arc method from a separated ion-plasma flux. In all the pressure ranges and bias voltage $\left(U_{\mathrm{RF}}=-100\right.$ and $\left.-200 \mathrm{~V}\right)$ under study, the $\mathrm{X}$-ray patterns of coatings applied onto steel substrates clearly exhibit diffraction reflections corresponding to a $(\mathrm{Zr}, \mathrm{Ti}) \mathrm{N}$ solid solution based on $\mathrm{ZrN}$ with a cubic lattice of the $\mathrm{NaCl}$ type.

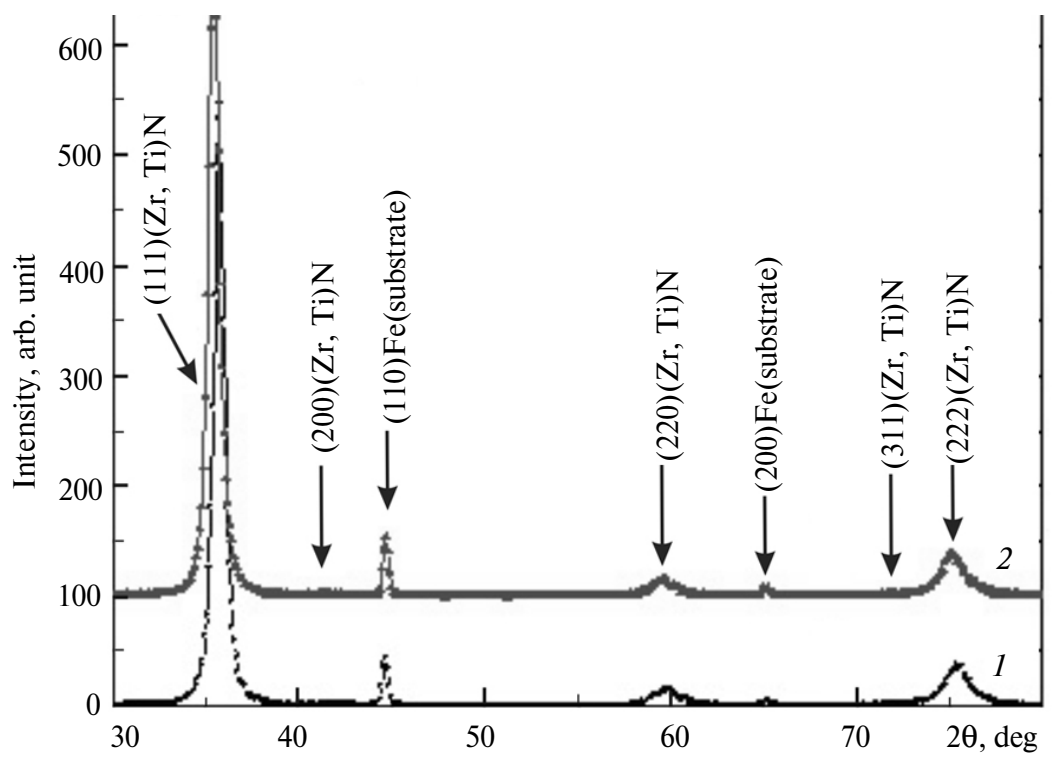

Fig. 2. Regions of X-ray patterns of (ZrTiSi) N coatings: $U_{\mathrm{RF}}=-200 \mathrm{~V}, p_{\mathrm{N}}=0.3 \mathrm{~Pa}(1), U_{\mathrm{RF}}=-200 \mathrm{~V}, p_{\mathrm{N}}=0.8 \mathrm{~Pa}(2)$. 
An increase of the bias voltage modulus from 100 to $200 \mathrm{~V}$ brings about the appearance and intensification of the growth texture with the $\{111\}$ plane parallel to the surface. In the range of the working pressures under study the size of crystallites varies slightly and is within $60-70 \mathrm{~nm}$. As the pressure increased, the macrodeformation varied from -2.6 to $-2.3 \%$, which corresponds to the effect of compression macrostresses $(8.0-$ 7.0 GPa).

An important advantage of multicomponent nanocomposite systems is in the fact that there is a possibility to produce superhard materials having close values of hardness but different values of the Young modulus (Table 3 ). This indicates that such coatings are characterized by the elastic failure strain $(E / H)$ and resistance to plastic strain $\left(E^{3} / H^{2}\right)$.

Table 3. Hardness and Young moduli of nanocomposite coatings from the $(\mathrm{Zr}-\mathrm{Ti}-\mathrm{Si}) \mathrm{N}$ and $(\mathrm{Ti}-\mathrm{Hf}-\mathrm{Si}) \mathrm{N}$ systems

\begin{tabular}{c|c|c|l}
\hline Coating & Hardness $H, \mathrm{GPa}$ & Young modulus $E, \mathrm{GPa}$ & \multicolumn{1}{|c}{ Comments } \\
\hline (Ti-Hf-Si)N & 42.7 & 390 & Sample 23 (see Table 2) \\
& 48.4 & 520 & Sample 37 (see Table 2) \\
& 39.7 & 383 & Sample 31 (see Table 2) \\
(Zr-Ti-Si)N & 37.1 & 429 & $U_{\mathrm{RF}}=-200 \mathrm{~V}, p_{\mathrm{N}}=0.3 \mathrm{~Pa}$ \\
& 33.1 & 392 & $U_{\mathrm{RF}}=-200 \mathrm{~V}, p_{\mathrm{N}}=0.8 \mathrm{~Pa}$ \\
\hline
\end{tabular}

Elastic characteristics of these coatings may essentially differ. A combination of high hardness and elastic recovery shows the unique nature of new nanocomposite coatings, namely, hard and at the same time elastic.

The studies of mechanical properties of the (TiHfSi) $\mathrm{N}$ coatings by nanoindentation showed that the maximum value of nanohardness was $H=48.4 \pm 1.4 \mathrm{GPa}$ and of elastic modulus $E=520 \pm 12 \mathrm{GPa}$. The maximum hardness of ( $\mathrm{ZrTiSi}) \mathrm{N}$ coatings is $37.1 \mathrm{GPa}$ and elastic modulus $429 \mathrm{GPa}$. After the vacuum annealing the solid solution partially decomposes, there forms amorphous phase of silicon nitrides, which causes a new structure-phase state. As a result the hardness of (ZrTiSi)N coatings increases to $48.6 \mathrm{GPa}$ and elastic modulus to $456 \mathrm{GPa}$ [10]. In this case the deformation observed in a coating corresponds to the compression stresses to $8.5 \mathrm{GPa}$.

It should be noted that rather high stresses are inherent in nitride films produced under high ionization, they contribute to a high adhesion of the film to a substrate and to development of compressive stress because of the so-called "atomic peening effect" [11].

By varying the bias voltage value during the deposition of (TiHfSi) $\mathrm{N}$ coatings, we control the energy of deposited particles, which promotes the decrease of nc-(Ti,Hf) N nanograins from 6.7 to $5.0 \mathrm{~nm}$ and the formation of the $\alpha-\mathrm{Si}_{3} \mathrm{~N}_{4}$ silicon-nitride phase (amorphous or quasi-amorphous interlayer between nanograins). These factors are responsible for the increase of the nanohardness of synthesized coatings from 42.7 to $48.4 \pm 1.4 \mathrm{GPa}$.

Table 4 gives the results of high-temperature tribotechnical testing of the ( $\mathrm{ZrTiSi}) \mathrm{N}$ and (TiHfSi) $\mathrm{N}$ coatings.

Table 4. Tribological characteristics of $(\mathrm{Zr}-\mathrm{Ti}-\mathrm{Si}) \mathrm{N}$ and $(\mathrm{Ti}-\mathrm{Hf}-\mathrm{Si}) \mathrm{N}$ nanocomposite coatings

\begin{tabular}{c|c|c|c|c}
\hline Coatings & $\begin{array}{c}\text { Temperature } \\
\text { of testing, }{ }^{\circ} \mathrm{C}\end{array}$ & $\begin{array}{c}\text { Coating wear intensity, } \\
\mathrm{mm}^{3} /(\mathrm{N} \mathrm{m})\end{array}$ & $\begin{array}{c}\text { Counterbody wear } \\
\text { intensity, } \mathrm{mm}^{3} /(\mathrm{N} \mathrm{m})\end{array}$ & $\begin{array}{c}\text { Friction coefficient, } \\
f_{\text {fr }}\end{array}$ \\
\hline (Zr-Ti-Si)N & 30 & $7.5 \times 10^{-5}$ & $1.9 \times 10^{-5}$ & 0.80 \\
& 300 & $2.2 \times 10^{-5}$ & $3.1 \times 10^{-5}$ & 0.71 \\
& 500 & $1.4 \times 10^{-5}$ & $2.8 \times 10^{-5}$ & 0.58 \\
$(\mathrm{Ti}-\mathrm{Hf}-\mathrm{Si}) \mathrm{N}$ & 30 & $2.5 \times 10^{-5}$ & $2.2 \times 10^{-5}$ & 0.26 \\
& 300 & $2.2 \times 10^{-5}$ & $3.1 \times 10^{-5}$ & 0.71 \\
& 500 & $1.5 \times 10^{-5}$ & $2.9 \times 10^{-5}$ & 0.63 \\
\hline
\end{tabular}

At the testing temperature $300^{\circ} \mathrm{C}$ a decrease in the coating wear is observed, while the wear of the counterbody increases. Later as the temperature increases to $500^{\circ} \mathrm{C}$, further decrease of the coatings wear is observed, i.e., with increasing temperature of the tests the wear resistance of the $(\mathrm{ZrTiSi}) \mathrm{N}$ and $(\mathrm{TiHfSi}) \mathrm{N}$ synthesized coatings increases. A temperature increase brings about a change of the conditions of the implementation of the processes taking place in the contact zone due to the changing of the structure of the coating material surface layers. To reveal the mechanism of above phenomenon, we performed additional studies of the friction 
surfaces. It was found that on the surfaces of friction trails there are $\mathrm{ZrO}_{2}, \mathrm{TiO}_{2}$ and $\mathrm{HfO}_{2}$ oxides and TiN, $\mathrm{Si}_{3} \mathrm{~N}_{4}$ nitrides, and $(\mathrm{Zr}$, Ti) $\mathrm{N}$ solid solution. Unlike the friction at room temperature, the friction at a high temperature is characterized by a more intensive oxidation and subsequent recovery of destructed oxide films. A change of the phase state in active layers occurs according to the specified thermobaric conditions and depends on the activity of diffusion processes. As a result of the above effects the redistribution of elements in the structural components, dissolution of finely dispersed inclusions, equalization of the degree of the heterogeneity through the depth of the active layer, and the development (on the attrition face) of the layers saturated with chemical elements from the medium during the friction. It should be kept in mind that tribochemical processes exert a favorable effect on antifriction properties of coatings only to certain friction conditions. The wear should not be assigned to any property of an oxide film. It is necessary to improve a set of characteristics like strength, brittleness, hardness, and strength of the oxide film adhesion to the surface of the basic metal. The interrelation of mechanical properties of materials, hardness in particular, with the temperature on the surface is discussed in [12, 13]. Similar assumptions were made in [14].

The results of our studies indicate that tribooxidation is an important and favorable process under the hightemperature friction conditions and it takes place far from the equilibrium state. We may separate some special features of this process as compared with a common isothermal oxidation. The tribooxidation of the $(\mathrm{ZrTiSi}) \mathrm{N}$ and (TiHfSi) $\mathrm{N}$ coatings results in a structural adaptation of surface layers to severe conditions of the high-temperature friction. The adaptation is a process based on a self-organization [15], as the result of which the wear resistance increases. Oxygen-containing metal compounds that form in the course of friction may act as a screen protecting the coating surface from a wear $[16,17]$.

The analysis of the adhesion strength shows that in the (TiHfSi) $\mathrm{N}$ coatings the cohesive fracture $\left(L_{C 2}\right)$ occurs at a load of $27.15 \mathrm{~N}$, in the (ZrTiSi) N coatings at $26.08 \mathrm{~N}$, and the plastic abrasion occurs at $55.24 \mathrm{~N}$ and $52.05 \mathrm{~N}$, respectively.

To define the degree of the influence of protective coatings on the efficiency of cutting tools, we developed a special composition of a coating based on the $(\mathrm{Ti}-\mathrm{Hf}-\mathrm{Si}) \mathrm{N}$ system and conducted production tests of cutters with inserts of $\mathrm{WC}-8 \mathrm{Co}$ hard alloy having $6 \mu \mathrm{m}$ thick protective coatings of the above composition. The tool geometrics was $\gamma=-8^{\circ}, \varphi_{1}=43^{\circ}, \varphi_{2}=47^{\circ}, \alpha=8^{\circ}$. The 12X18H10T grade steel was turned on a 16A20F3 lathe at the following parameters: cutting speed $v=3.0 \mathrm{~m} / \mathrm{s}$, feed $S=0.25 \mathrm{~mm} / \mathrm{rev}$, depth of cut $t=0.5 \mathrm{~mm}$. Figure 3 shows the results of testing cutting tools with two types of protective coatings based on the (Ti-Hf$\mathrm{Si}) \mathrm{N}$ system and of titanium nitride.

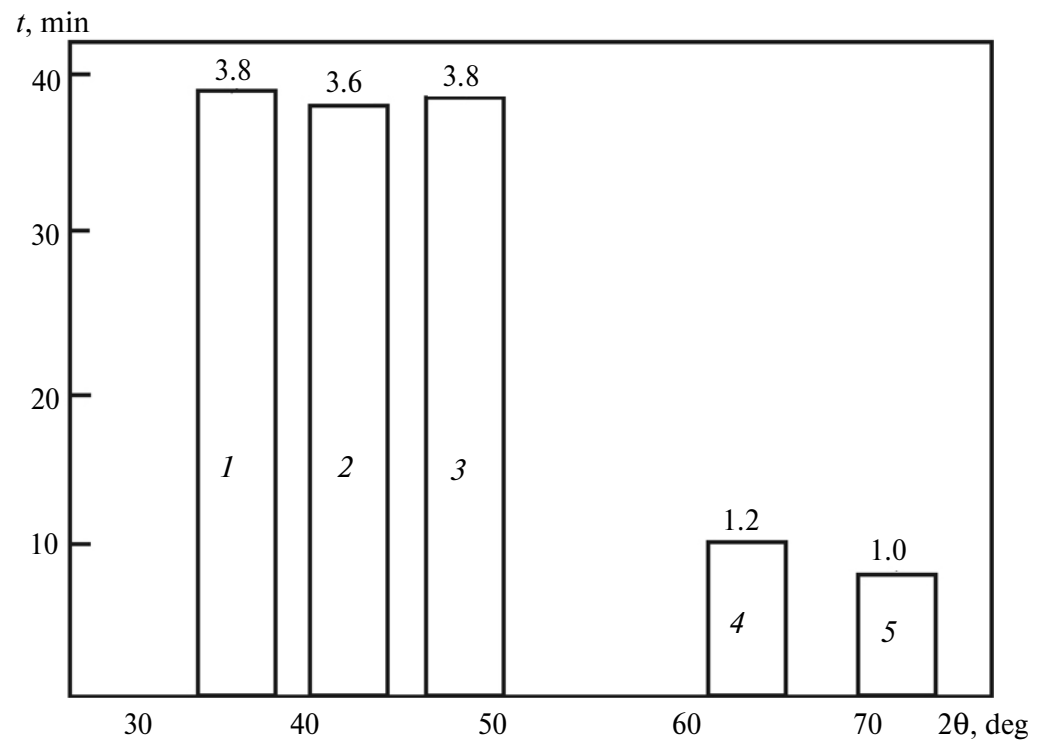

Fig. 3. Diagram of the life of tools with $\mathrm{WC}-8 \mathrm{Co}$ hard alloy inserts with coatings (in wt $\%$ ) $50 \mathrm{Ti}, 35 \mathrm{Hf}, 10 \mathrm{Si}$, the rest being $\mathrm{N}(1-3)$, TiN coating (4), without coating (5) in turning the $12 \mathrm{X} 18 \mathrm{H} 10 \mathrm{~T}$ grade steel: $v=3.0 \mathrm{~m} / \mathrm{s}, s=0.25 \mathrm{~mm} / \mathrm{rev}, t=0.5 \mathrm{~mm}$.

It is seen from the data that the use of (TiHfSi) $\mathrm{N}$ protective coatings ensures an increase of the cutting tool efficiency in turning $12 \mathrm{X} 18 \mathrm{H} 10 \mathrm{~T}$ grade steel by a factor of more than 3 as compared with a tool having a TiN protective coating and by a factor of 4 as compared with a tool without coating.

Thus, our studies and production tests give ground to characterize the obtained (TiHfSi) N superhard coatings as effective protective coatings for cutting tools. 


\section{CONCLUSIONS}

Coatings based on the $(\mathrm{Zr}-\mathrm{Ti}-\mathrm{Si}) \mathrm{N}$ and $(\mathrm{Ti}-\mathrm{Hf}-\mathrm{Si}) \mathrm{N}$ systems have been produced by vacuum-arc deposition using a RF generator and separation of an ion-plasma flux. The coatings are characterized by the absence a drop fraction, high physico-mechanical and tribotechnical properties.

It has been shown that as the modulus of the bias voltage increases from 100 to $200 \mathrm{~V}$, a degree of texturing the (ZrTiSi)N and (TiHfSi) N coatings increases and the mean size of crystallites decreases.

The maximum hardness and the elastic modulus of the ( $\mathrm{ZrTiSi}) \mathrm{N}$ coatings produced by a separated ionplasma flux have been found to be $H=37.1 \mathrm{GPa}, E=429 \mathrm{GPa}$. Similar characteristics for the (TiHfSi)N coatings were $H=48.4 \mathrm{GPa}, E=520 \mathrm{GPa}$.

It has been shown that the increasing temperature of tribotechnical tests of synthesized $(\mathrm{ZrTiSi}) \mathrm{N}$ and (TiHfSi) $\mathrm{N}$ coatings from 300 to $500^{\circ} \mathrm{C}$ is accompanied by an increasing wear resistance and improvement of frictional properties of the coatings.

The use of the resulting coatings for WC-8Co cutting tools contributes to the efficiency of the tools in turning the $12 \mathrm{X} 18 \mathrm{H} 10 \mathrm{~T}$ grade steel by a factor of more than 3 , which allows us to consider them as effective protective coatings.

\section{REFERENCES}

1. Koch, K., Ovil'ko, I., Sil, S., and Veprek, S., Konstruktsionnye nanokristallicheskie materialy. Nauchnye osnovy $i$ prilozheniya (Structural Nanocrystalline Materials. Scientific Principles and Applications), Moscow: Fizmatlit, 2012.

2. Pogrebnjak, A.D., Shpak, A.P., Azarenkov, N.A. and Beresnev, V.M., Structure and properties of Hard and Superhard Nanocomposite Coatings, Physics-Uspekhi, 2009, vol. 179, no. 1, pp. 35-64.

3. Berlin, E.V. and Seidman, L.A., Ionno-plazmennye protsessy v tonkoplenochnoi tekhnologii (Ion-Plasma Processes in the Thin-Film Technology), Moscow: Tekhnosfera, 2010.

4. Aksenov, I.I., Andreev, A.A., Belous, V.A., et al., Vakuumnaya duga: istochniki plazmy, osazhdenie pokrytii, poverkhnostnoe modifitsirovanie (Vacuum Arc: Plasma Sources, Deposition of Coatings, Surface Modification), Kiev: Naukova Dumka, 2012.

5. Beresnev, V.M., Shvets, O.M., and Belyaeva, T.N., Special Features of the Input of a High-Frequency Energy by a Plasma Stream, Physical Engineering of Surface, 2005, vol. 3, nos. 1-2, pp. 71-73.

6. Shvets, O.M., Beresnev, V.M., and Turbin, P.V., et al., The Use of a Pulse RF-Oscillator with a Shock Circuit in a Vacuum-Arc Deposition when Synthesizing Nanostructured Coatings, ibid., 2011, vol. 9, no. 1, pp. 32-39.

7. Pogrebnjak, A.D., Shpak, A.P., Beresnev, V.M., et al., Stoichiometry, Phase Composition, and Properties of Ti-Hf-SiN Superhard Nanostructural Films Produced by a Vacuum-Arc Source in a High-Frequency Discharge, PZhTF, 2011, vol. 37, no. 13, pp. 90-97.

8. Pogrebnjak, A.D., Sobol, O.V., Beresnev, V.M., et al., Phase Composition Thermal Stability, Physical and Mechanical Properties of Superhard on Base $\mathrm{Zr}-\mathrm{Ti}-\mathrm{Si}-\mathrm{N}$ Nanocomposite Coatings, Nanostructured Materials and Nanotechnology IV: Ceramic Eng. Sci. Proc., 2010, vol. 31, no. 7, pp. 127-138.

9. Azarenkov, N.A., Sobol', O.V., Pogrebnjak, A.D., and Beresnev, V.M., Inzheneriya vakuumno-plazmennykh pokrytii (Engineering of Vacuum-Plasma Coatings), Khar'kov: Karazin Khar'kov National University, 2011.

10. Pogrebnjak, A.D., Shpak, A.P., Beresnev, V.M., et al., Effect of Thermal Annealing in Vacuum and Air on Nanograin Sizes in Hard and Superhard Coatings ZrTiSiN, J. Nanosci. Nanotech., 2012, vol. 12, pp. 9213-9218.

11. Kelly, P.J. and Arnell, R.D., Magnetron Sputtering: a Review of Recent Developments and Applications, J. Vacuum, 2000, vol. 56, pp. 159-172.

12. Beresnev, V.M., Sobol, O.V., Pogrebnjak, A.D., et al., Thermal Stability of the Phase Composition, Structure, and Stressed State of Ion-Plasma Condensates of the Zr-Ti-Si-N System, ZhTF, 2010, vol. 80, issue 6, pp. 117-120.

13. Myshkin, N.K. and Petrokovets, M.I., Trenie, smazka, iznos. Fizicheskie ocnovy I tekhnicheskie prilozheniya tribologii (Friction, Lubrication, Wear. Physical Principles and Technical Applications of Tribology), Moscow: Fizmatlit, 2007.

14. Sobol, O.V., Pogrebnjak, A.D., and Beresnev, V.M., Effect of the Preparation Conditions on Phase Composition/Structure, and Mechanical Characteristics of Vacuum-Arc Zr-Ti-Si-N Coatings, Phys. Metals Metallography, 2011, vol. 112, pp. 199-206.

15. Beresnev, V.M., Kaverin, M.V., Akhmed, M.M., Smolyakova, M.Yu., Kolesnikov, D.A., Kirik, G.V., Komarov, F.F., Grudnitskii. V.V., and Nemchenko, U.S., Tribotechnical Properties of Ti-Zr-Si-N Nanocomposite Coatings Deposited by an Ion-Plasma Method, Friction and Wear, 2012, vol. 33, no. 3, pp. 215-222.

16. Krioni, N.K., Migranov, M.Sh., and Shuster, L.Sh., Composite Materials with a Predictable Adaptation in Fracture and Cutting Metals, Vestnik UGATU, 2009, vol. 12, no. 2 (31), pp. 88-92.

17. Matsevityi, V.M., Kazak, I.B., and Vakulenko, K.V., Fiziko-tekhnicheskie aspekty adgezii tverdykh tel (Physico-Technical Aspects of Adhesion of Solids), Kiev: Naukova Dumka, 2010. 